ARCHIVO ESPAÑOL DE ARTE, LXXXVI, 343

JULIO-SEPTIEMBRE 2013, pp. 221-236

ISSN: 0004-0428

\title{
LA MIRADA DE EUDALD SERRA. EL ARTISTA A TRAVÉS DE LAS COLECCIONES DE CERÁMICA JAPONESA DEL MUSEO ETNOLÓGICO DE BARCELONA ${ }^{1}$
}

\author{
Muriel Gómez Pradas
}

\begin{abstract}
El principal objetivo de este artículo es mostrar como las preferencias estéticas, la sensibilidad, y, muy especialmente, la particular "mirada" del escultor Eudald Serra (Barcelona 1911-2002) definen y caracterizan de una manera muy concreta la colección japonesa que este artista adquirió para el Museo Etnológico de Barcelona e influyó también en su propia obra. Ha sido precisamente el conocimiento y estudio de dicha colección, concretamente el grupo de obras de cerámica japonesa, la que nos ha permitido conocer tanto al hombre como al artista, habiendo sido absolutamente imprescindible para ellos el trabajo con material inédito como sus Diarios personales de viaje.
\end{abstract}

Palabras clave: Eudald Serra; Mingei; Japón; Abstracción; Figuración; Cerámica; MEB-Museo Etnológico de Barcelona.

\section{THE GAZE OF EUDALD SERRA. THE ARTIST SEEN THROUGH THE COLLECTIONS OF JA- PANESE CERAMICS IN THE ETHNOLOGICAL MUSEUM OF BARCELONA}

The main objective of this paper is to analyze how the aesthetic preferences, sensitivity and particular "gaze" of the sculptor Eudald Serra (Barcelona 1911-2002) define and characterize the Japanese collection acquired by him for the Ethnological Museum of Barcelona, and influenced his own work as well. Precisely the knowledge and study of this collection, specifically the Japanese pottery, allowed us to understand both the man and the artist. His personal Travel Diary along with other unpublished materials have been essential in carrying out this work.

Key words: Eudald Serra; Mingei; Japan; Abstraction; Figurative; Pottery; MEB- Ethnological Museum of Barcelona.

\footnotetext{
${ }^{1}$ Este articulo surge como parte de las investigaciones llevadas a cabo para la tesis doctoral así como del trabajo con el grupo de investigación "Japón y España: relaciones a través del Arte" en los dos proyectos I+D concedidos por el Ministerio de Educación y Ciencia: Catalogación y estudio de las colecciones de arte japonés tradicional y contemporáneo en España (museos públicos y privados) (HAR 2008-05784) y Inventario y catalogación de arte japonés en museos e instituciones públicas y museos privados en España (HUM2005-05188).
} 
Eudald Serra i Güell (Barcelona, 1911-2002)2 siempre se definió como un escultor, a pesar de que fue una figura absolutamente poliédrica, en la cual se aunaban la mirada y el saber de un escultor, un ceramista, un pintor, un dibujante, un fotógrafo y un coleccionista. Fue, además, un infatigable viajero que tuvo siempre muy presente la idea del viaje como proceso y elemento de conocimiento y aprendizaje, tanto del otro como muy especialmente de uno mismo y del mundo que lo rodeaba. Un escultor con una personal mirada; con una innata e ilimitada curiosidad por conocer y saber que lo llevó a una búsqueda constante de la belleza en una trayectoria personal y vital única, que lo condujo a buscarla y descubrirla incluso en las obras más humildes, sencillas y cotidianas.

El objetivo de este artículo es presentar el gusto y las preferencias estéticas de Eudald Serra, y para ello nos centraremos en la colección de cerámica japonesa seleccionada por él mismo para el Museu Etnològic de Barcelona (MEB, en adelante), fundado en 1948 por el Ayuntamiento de Barcelona e inaugurado en febrero de $1949^{3}$. En ese mismo año se conocieron Serra y el entonces director del MEB, August Panyella, iniciándose así una relación de colaboración entre Serra y el museo que duró prácticamente hasta el final de su vida. Como se verá, Eudald Serra seleccionó las piezas de las colecciones japonesas del MEB basándose más en criterios personales que en las pautas científicas de la época. Por este motivo, es posible afirmar que tras cada objeto seleccionado por Serra para la colección del MEB puede observarse muy claramente al propio Serra, al artista.

Y ha sido precisamente el conocimiento y estudio de dichas colecciones la que nos ha permitido conocer tanto al hombre como al artista. Y para ello ha sido absolutamente imprescindible el cotejo y trabajo con sus Diarios personales de viaje ${ }^{4}$, una memoria histórica y personal que nos ha permitido establecer tanto sus gustos estéticos y personales como su sistema de trabajo. Esta documentación es en realidad una mezcla de datos técnicos, estado de cuentas pero también de memoria personal y vivencial, como se puede constatar en la siguiente anotación

13-5-1961 Tokyo-Nagoya: Salgo precipitadamente de Tokyo para Nagoya, por la mañana recibí carta de Panyella anunciándome habían entregado el dinero a Antonio. Me habla de la exposición de Nepal, parece que ha sido un éxito. Esto me da un poco de ánimos. El tiempo es corto por el trabajo que tengo que hacer. En Nagoya tomo un autobús hasta Seto, me esperaba el pintor Kitagawa amigo de Hilikata, habla muy bien español, cenamos juntos y preparamos el plan de trabajo para mañana. Me conduce al hotel japonés, antiguo pero limpio, unas dos habitaciones de diez tatamis cada una dan sobre un magnífico jardín japonés de arbustos, pinos y piedras. He tomado mi baño en una habitación mezcla de gresita y roca natural. Me siento muy solo ${ }^{5}$.

\footnotetext{
${ }^{2}$ Para una aproximación biográfica a su figura véase el catálogo de la exposición Eudald Serra. Rastres de vida (1998) así como la tesis doctoral de Gómez PradAs, 2011: 65-86.

${ }^{3}$ Para información detallada sobre la historia del museo véase, entre otras, las publicaciones de HuERA, 1993: 160164 y HUERA, 1995: 151-163.

${ }^{4}$ He de agradecer la colaboración de la familia de Eudald Serra, y muy especialmente la de su nieto Ramiro Córdoba, que me facilitó el acceso a la transcripción de los diarios de los viajes, en los cuales encontramos tanto datos personales como documentación técnica. Es especialmente interesante el diario del viaje realizado en el año 1961 ya que los comentarios que contiene veremos que ayudan a definir y a entender su gusto y apreciación estética, elementos clave para comprender las características específicas de las colecciones del MEB.

${ }^{5}$ En la transcripción consultada del documento original manuscrito, realizada por Agustina Valls entre los años 1998 y 2000, no se hace referencia a las características del documento original ni a las páginas, y tampoco está numerado el documento en DIN A4 de dicha transcripción. Por ello, siempre que se mencione se citará el día, para que sirva de referencia ya que el diario está ordenado cronológicamente, siguiendo la expedición que tuvo lugar entre el 9 de mayo y el 6 de julio de 1961.
} 
Este museo barcelonés destaca por su extensa colección japonesa formada por más de 3.300 objetos $^{6}$ de una gran variedad tipológica. De esta amplia colección, en este artículo únicamente nos centraremos en un grupo: las obras que llegaron a Barcelona gracias a las expediciones a Japón dirigidas por Eudald Serra en los años 1957, 1961 y 19647. Y muy en concreto, por su importancia y cohesión interna que tienen, en un grupo de unos 500 objetos cerámicos, prominentes mayoritariamente de la expedición de 1961. Dicha coherencia debe agradecerse precisamente a la figura de Eudald Serra, gran conocedor de Japón y de su cultura gracias, entre otras razones, a los trece años que vivió allí y a su conocimiento del Mingei Undo 民芸運動.

A pesar de que queda fuera del alcance de este artículo explicar en qué consistió realmente el Mingei Undo $o^{8}$, cuáles fueron sus características e influencias posteriores, es importante contextualizarlo de manera breve por la influencia que tuvo en Serra este movimiento. Se trata de un movimiento de revitalización del arte popular de Japón que nació en las primeras décadas del siglo XX, aunque no fue hasta los años 50, y especialmente los 60 , cuando empezó a tener reconocimiento nacional y, especialmente, internacional - gracias a la figura y al trabajo del ceramista inglés Bernard Leach $^{9}$-. Y estos son precisamente los años de las expediciones realizadas por el MEB a Japón.

El Mingei Undo ${ }^{10}$ surgió en pleno periodo Taishô (1912-1926) ${ }^{11}$-a imagen del Arts and Crafts Movement inglés de William Morris (1834-1896) ${ }^{12}$-, como un proceso de revitalización del arte popular de Japón y como reacción al proceso de industrialización del país. Fue una filosofía idealizada de la producción artesanal cuyo principal ideólogo fue Yanagi Soetsu (1889-1961) $)^{13}$, además de constituir un medio para preservar miles de objetos artesanales ${ }^{14}$.

Para que un objeto fuera considerado como verdaderamente mingei, tenía que cumplir una serie de requisitos que podríamos concretar y definir, siguiendo el ideario propuesto por Yanagi, en los siguientes puntos. Estos objetos tenían que ser: (1) funcionales, ya que de su funcionalidad deriva su belleza ${ }^{15},(2)$ comunes, cotidianos, utilizados por la gente común diariamente, (3) hechos

\footnotetext{
${ }^{6}$ Para una aproximación a ésta colección miscelánea y de tipología muy variada, puede consultarse la tesis doctoral Gómez PradAs, 2011: 55-64.

${ }^{7}$ Hubo dos tipos de expediciones: las realizadas por Serra en solitario y las realizadas junto con el entonces director del MEB, August Panyella. En las primeras, los gastos de viaje y estancia fueron subvencionados por el coleccionista don Albert Folch, mientras que el presupuesto para las adquisiciones quedaron a cargo del Ayuntamiento barcelonés (el caso de los viajes a Japón de 1957 y 1961). En las segundas, los gastos de viaje y estancia de Serra fueron subvencionados por el coleccionista Albert Folch, mientras que los de Panyella, así como el presupuesto para adquisiciones corrieron a cargo del consistorio barcelonés (la expedición de 1964). Para un estudio en profundidad de estas expediciones, así como de la gran variedad de objetos seleccionados y comprados, puede consultarse la tesis doctoral GómEZ PrADAs, 2011: 71-82.

${ }^{8}$ Para información detallada sobre el movimiento Mingei véase las recientes publicaciones de BRANDT (2007) y KIKUCHI (2004), así como también MoERAN (1997).

${ }^{9}$ Entre la numerosa e interesante bibliografía existente sobre la figura y la trascendencia de la figura de Bernard Leach en relación al movimiento Mingei, destacar el artículo de De WAAL, 1997: 355-362.

${ }^{10}$ El Mingei Undo se suele traducir al inglés como Japanese Folk Craft Movement.

${ }^{11}$ Un momento histórico complejo en el que empezaron a surgir diversos problemas (especialmente ideológicos y filosóficos) provenientes en gran parte de la asimilación o equiparación realizada durante el período Meiji (1868-1912) entre modernización y occidentalización. Una reacción que se plasmó en el auge del nacionalismo cultural, nacionalismo que se concretó en el período Showa (1926-1989).

${ }^{12}$ Uno de los primeros en iniciar el debate sobre la originalidad de Yanagi, mostrando los paralelismos existentes con el Arts and Crafts de Morris y Ruskin, fue MoERAn, 1980: 25-26.

${ }_{13}$ Para una biografía completa de Yanagi Soetsu es muy recomendable el artículo de Utsumi, 1995: 14-31.

${ }^{14}$ El Mingei Undo también tuvo una importante parte práctica en la preservación del patrimonio, especialmente a partir de la fundación en 1936 por parte de Yanagi de un museo, el Nihon Mingeikan, concebido como un medio para preservar los objetos mingei y donde poder establecer y exhibir su estándar de belleza.

${ }^{15}$ El mismo Yanagi lo resume perfectamente en una sola frase al decir que lo esencial "es la belleza nacida del uso", YANAGI, 1989: 197.
} 


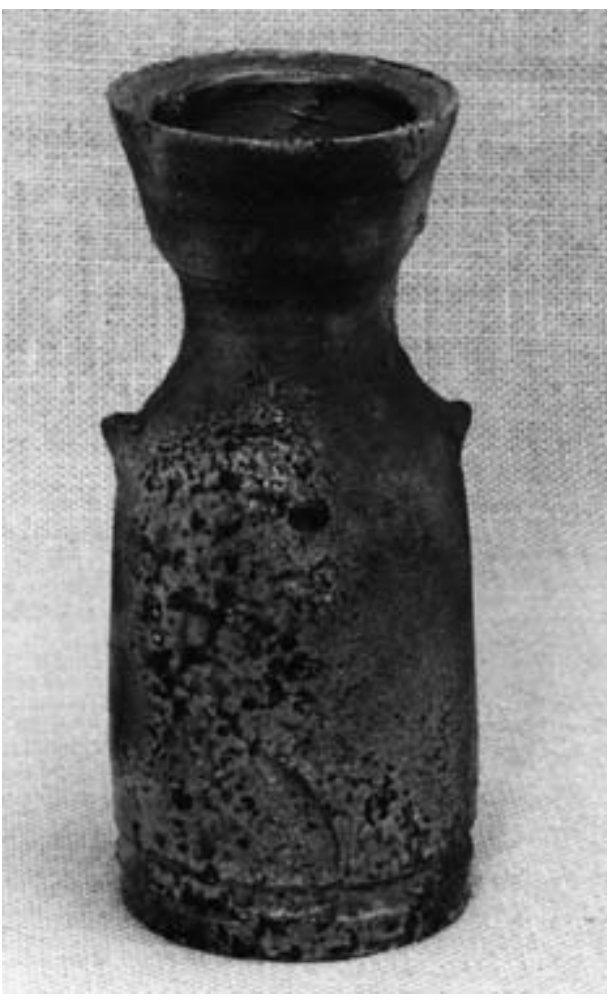

Fig. 1. Fujiwara Yu, Florero. Horno Bizen, prefectura de Okayama, Japón. Cerámica, 23.5

x Ø $10 \mathrm{~cm}$. (C) Fotografía Pilar Aymerich cortesía del Museu Etnològic de Barcelona.

a mano, (4) anónimos y (5) realizados con materiales naturales (fig. 1).

Uno de los conceptos básicos del Mingei undo que más destacaba Yanagi era la idea de la no individualidad. Consideraba que la belleza no podía nacer del trabajo asalariado, ni tampoco de la individualidad o genialidad de una persona. En una entrevista realizada a Yanagi en 1927, le preguntaron por qué creía que las obras de los artesanos anónimos eran mejores que las de los artistas, a lo que respondió que mientras que el artista está sujeto a su propio ego y a una búsqueda constante de formas particulares de expresión que lo destaquen e individualicen, el artesano se deja guiar por la tradición, la naturaleza y la humildad ${ }^{16}$. Pero en realidad aquí se halla una de las contradicciones más claras y evidentes del movimiento Mingei: el reconocimiento de la personalidad creadora -como ocurrió con Kawai Kanjiro o Hamada Shoji ${ }^{17}$ por citar sólo dos ejemplos-, entraba en total contradicción con las ideas de Yanagi. Además, este reconocimiento artístico hizo que se realizaran un número más limitado de objetos y que se incrementara su precio, con lo cual dejaban de ser objetos de uso cotidiano para la gente común y pasaban a tener categoría de objetos para la élite, algo totalmente contrario a las ideas expuestas por Yanagi. A ello debe añadirse que al tratarse de objetos casi únicos, la gente no los utilizaba por temor a romperlos; con lo cual se anulaba su funcionalidad y pasaban a convertirse en objetos decorativos, es decir, en objetos "artísticos". Por lo tanto, pese a esta idea de la no individualidad y del no-reconocimiento de la personalidad artística, en la mayoría de museos dedicados al Mingei encontramos obras de artistas reconocidos, y veremos que el MEB también es un claro ejemplo de ello.

\section{Eudald Serra. De Barcelona a Japón}

Una premisa básica a tener en cuenta es la formación de Eudald Serra como escultor, formación que contribuyó a su sensibilidad y gusto estético. Serra, nacido en el seno de una familia de la burguesía barcelonesa, estudió en la Escola d'Arts i Oficis de Barcelona (Llotja), donde ingresó

\footnotetext{
16 YANAGI, 1989: 199.

17 El MEB tiene obras de Hamada pero no de Kawai Kanjiro ya que, tal y como expone E. Serra en la anotación del día 19 de mayo de 1961, los elevados precios de este reconocido artista fueron un obstáculo insalvable para que pudiese adquirir obra para el museo "19-5-61: viernes Kyoto (...). Kawai Kanjiro, no me acabo de decidir debido a los precios".
} 
en 1929 y fue discípulo del escultor Ángel Ferrant ${ }^{18}$. Se integró en el grupo ADLAN (Amics de l'Art Nou), fundado en 1932 por Ferrant con la idea de promover toda una serie de actividades culturales encaminadas a la difusión de nuevos lenguajes artísticos. Así, antes de partir hacia Japón, ya había realizado una exposición de esculturas y dibujos en la Sala Busquets de Barcelona en $1934^{19}$, y había participado en una exposición colectiva en la Galería Catalonia junto a Ramón Marinel-lo y Jaume Sants en 1935. Esta última exposición, junto con dos de los destacados discípulos de Ferrant, y con un extraordinario cartel realizado por Salvador Ortiga ${ }^{20}$, fue un hito dentro del panorama artístico barcelonés de la época ${ }^{21}$, ya que seguían el camino iniciado por su maestro en la utilización de elementos y objetos cotidianos como materiales artísticos, alejándose así del lenguaje formal favorecido desde la academia. Lamentablemente, de la mayoría de las obras realizadas por Serra en estos primeros años únicamente se conserva alguna fotografía.

A pesar del éxito artístico que estaba empezando a cosechar, ese mismo año, con sólo 24 años, partió de viaje hacia Japón con un grupo de estudiantes de la Universidad de Barcelona. La motivación que le indujo a llevar a cabo este viaje fue meramente personal, quizás influido por la falta de reconocimiento paterno a la actividad artística a la que se quería dedicar. Años más tarde, en una entrevista publicada en 1953 en La Vanguardia el periodista le preguntaba el porqué de irse tan lejos, respondiendo Serra con su habitual humor, "Fue el azar; tres bolitas: África, Asia Menor y Extremo Oriente; salió ésta" ${ }^{, 22}$.

Tras llegar a Japón en 1935 cambia radicalmente de estilo artístico, pasando de una estética cercana a los ready-made, donde los materiales y los objetos son la esencia, a un claro figurativismo, aunque como veremos más por necesidad que otra cosa, ya que una vez en Japón, circunstancias personales pero muy especialmente circunstancias históricas hicieron que su estancia se alargara más de lo previsto. Eudald Serra vivió en Japón entre 1935 y 1948, un período históricamente difícil y que lo marcaría profundamente. Al principio de su estancia en el país nipón trabajó en el consulado de España en Kobe pero, a inicios de la guerra civil española fue despedido al negarse a regresar a España para alistarse ${ }^{23}$. Serra se trasladó a uno de los lugares más humildes de Kobe, la playa, donde un escultor amigo le cedió un espacio para vivir en su casa. En la playa de Kobe compartía subsistencia con otros artistas y con emigrantes coreanos ${ }^{24}$. Poco a poco retomó la práctica de esculpir y pasó de sus inicios como artista cercano a la poética y estética surrealista y los ready-made, a cincelar en directo; primero a sus vecinos coreanos y luego retratando a todos

\footnotetext{
18 Ángel Ferrant (Madrid 1890-1961), escultor y pedagogo. A principios de la década de los 20, traslada su plaza de profesor a Barcelona, concretamente a Llotja. De sus años en Barcelona destacan especialmente sus actividades pedagógicas -totalmente novedosas para la época y que obtuvieron una gran resonancia-, así como la fuerte impronta que dejó en sus alumnos, entre los que destacan Jaume Sans, Ramon Marinel·lo y Eudald Serra. Realmente, Ferrant y sus discípulos fueron un revulsivo en la escena artística barcelonesa al optar por una vía absolutamente experimental y prescindir de las técnicas escultóricas más tradicionales y académicas. En 1934 se traslada a Madrid, donde proseguirá hasta el final de su vida su labor de profesor en la Escuela de Artes y Oficios. Para un perfil biográfico más detallado, véase por ejemplo la web del Museo Patio Herreriano de Valladolid, donde se conserva el Fondo Ángel Ferrant: http://www.museopatioherreriano.org/AngelFerrant/perfil_biografico (consultada el 5 de junio de 2012).

Sobre la labor pedagógica de Ángel Ferrant véase el interesante artículo de AsENJo FeRnándEZ, 2009: 47-62 y sobre su labor artística BOZAL, 1995: 175-179.

19 "Eudaldo Serra, escultor", La Vanguardia, 28-02-1934: 10.

${ }^{20}$ Se conserva un ejemplar en el Museu Nacional d'Art de Catalunya (MNAC no inventario 214185-000).

${ }^{21}$ La exposición tuvo lugar entre el 27 y el 30 de marzo de 1935. Una de las notas aparecidas en la sección de "Arte y Artistas" de La Vanguardia de esos días explica cómo, debido a la gran afluencia de público, se acordó abrir incluso el domingo. "ADLAN", La Vanguardia, 30-03-1935: 11.

${ }_{22}^{2}$ Del Arco, 1953: 13.

${ }^{23}$ Información obtenida gracias a su sobrino nieto, Pepe Serra, a quien hemos de agradecer su colaboración.

${ }^{24}$ Los coreanos estaban en uno de los escalafones más bajos de la sociedad japonesa.
} 


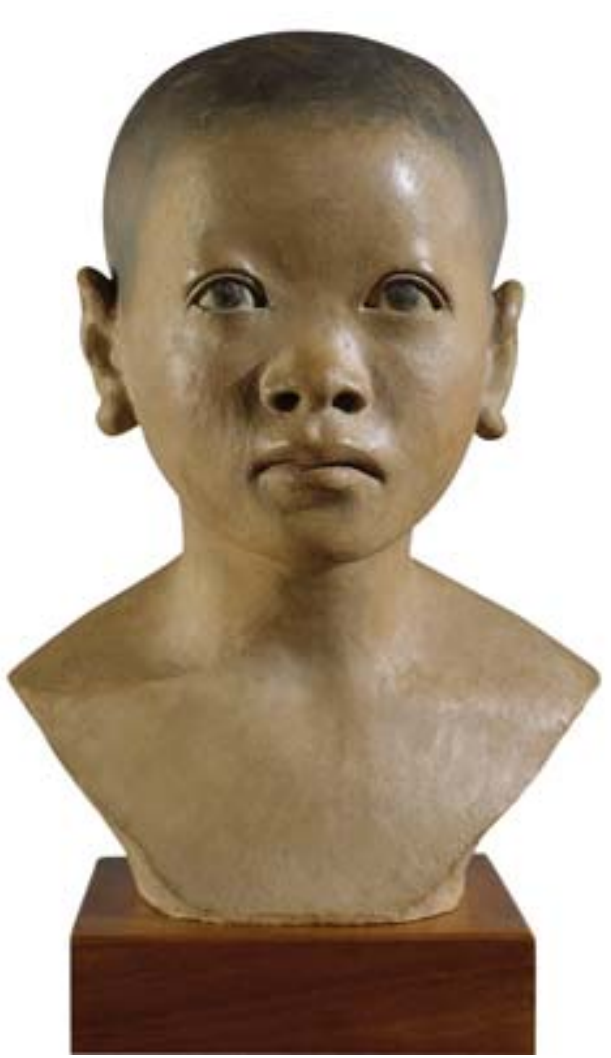

Fig. 2. Eudald Serra, Coreano, 1937. Terracota policromada, 30,2 x 21,2 x $18 \mathrm{~cm}$. (C) MNAC Museu Nacional d'Art de Catalunya, Barcelona. aquellos personajes que le parecían interesantes ${ }^{25}$. Del más puro arte de vanguardia a la figura humana más tradicional. Un cambio radical y en ocasiones complejo de entender si no fuera por el hecho de que para Eudald Serra la polémica o contraposición entre abstracción y figurativismo era inexistente, ya que "la esencia es una, todo es lo mismo. El verdadero arte está en las formas que se valen por sí mismas. La forma nace de la imaginación del hombre y se nutre de los lugares, del tiempo, de los momentos y de su pasaje ${ }^{, 26}$ (fig. 2).

Al hablar de las particulares características de estas esculturas, el propio Serra explicaba que él realizaba "antropología plástica (...), es decir, «hago» las cabezas de los aborígenes sin la precisión científica del antropólogo que mide los centímetros del cráneo sin apenas importarle que hay debajo de él"27. Es interesante subrayar esta reflexión de Serra porque constata personalmente, de manera clara y sin ambages, que su aproximación a la figura es eminentemente plástica. No podemos olvidar que el modelado de estos bustos se inició sin ningún tipo de objetivo documental o científi$\mathrm{co}^{28}$, sino por la simple razón de que eran los modelos que tenía más a mano y con los que convivía en la playa de Kobe. Además es interesante constatar cómo, mientras tradicionalmente el arte del retrato ha servido para individualizar y perpetuar la memoria de hombres ilustres, Serra en realidad da a sus retratos el significado contrario, ya que a través "de un hombre retrata un pueblo"29.

Este aspecto es realmente importante ya que su aproximación al objeto partirá de estas mismas premisas plásticas y, por lo tanto, será absolutamente diferente de la que podía tener un antropólogo o un etnógrafo. Mientras que la antropología durante muchos años no se interesó por los aspectos artísticos de las culturas y pueblos que estudiaba ${ }^{30}$, Serra se movía motivado por su experiencia artística y por su propia sensibilidad; por su gusto por

${ }^{25}$ Se trataba de bustos que se convertirían para Eudald Serra en una de las constantes de todos los viajes que posteriormente realizó con el Museo Etnológico y con la Fundación Folch por todo el mundo. Actualmente, 53 de estas esculturas forman parte de las colecciones del Museo Etnológico de Barcelona (véase el catálogo de la exposición Escultures antropològiques d'Eudal Serra i Güell (1991), y el resto se conservan en la Fundación Folch y en la propia colección del autor, gestionada actualmente por sus nietos.

${ }^{26}$ ZaBalbeascoA, 1998: 112-113.

27 Llopis, 1964: 45.

${ }_{28}$ Aunque posteriormente, y desde el Museu Etnològic de Barcelona, sí se les dio importancia como documento.

29 Vélez, 2002: 373. Un ejemplo claro lo tenemos en el busto del ainu Miyamoyo, un hombre de 40 años de la costa meridional de Hokkaido modelada por E. Serra primero en barro en 1947. En 1949, el MEB adquirió esta obra y se pasó a piedra calcárea (MEB 3-1). Durante muchos años este retrato ha servido para ejemplificar y definir quienes eran, y especialmente cómo eran, los ainu.

${ }^{30}$ LÓPEZ, 1997: 12. 
los objetos cotidianos, por los materiales sencillos y comunes, por las texturas y por las vivencias y la belleza que estos transmitían. Un hecho a destacar, teniendo en cuenta que tras regreso a Barcelona en 1948, Serra empezó a colaborar precisamente con el recién inaugurado museo de etnología de la ciudad, para el que acabo dirigiendo numerosas expediciones de compra por todo el mundo, siendo de las más destacadas las realizadas a Japón en 1957, 1961 y 1964 como ya hemos visto.

A Eudald Serra le gustaba recalcar ${ }^{31}$ que la selección de objetos que efectuó para el MEB en estas expediciones la realizó pensando en traer ejemplos de elementos representativos del arte y la cultura popular japonesa de los años 50; pero sobre todo, lo que a él le interesaba era conseguir ejemplos distintivos de aquello que consideraba importante y que se estaba perdiendo. En una entrevista realizada en 1964, al regreso de una expedición a los Andes, Serra realizó unas declaraciones que bien podrían servir también para identificar el tipo de objetos seleccionados en Japón:

No se trataba de buscar objetos de valor material, piezas antiguas y ricas, cosas difíciles de encontrar, y más difíciles aún de salir del país o de los países donde se adquieren, sino dar con materiales bellos y utilitarios que hablan de la vida de los pueblos que los fabrican y los usan y nos evocan sus oscuras existencias y hasta qué extremo aman las formas y saben elaborar esas piezas simples, pero siempre llenas de gracia cuando salen de manos artesanas; modelos que se repiten a lo largo de los años y que poseen una absoluta vigencia por su utilidad y por su uso constante ${ }^{32}$.

Es decir objetos "reales", cotidianos y útiles: objetos como los ensalzados por el Mingei Undo así como el tipo de objetos y materiales con los que se formó e inició su carrera como escultor en la Barcelona de inicios de la década de $1930^{33}$.

\section{Eudald Serra y la cerámica japonesa}

Entre los objetos mingei más representados en el MEB se encuentra la cerámica. Un hecho lógico, teniendo en cuenta que los fundadores del Mingei Undo junto a Yanagi fueron ceramistas y que, como señala Brian Moeran ${ }^{34}$, los ceramistas fueron los más beneficiados del boom del Mingei a finales de los años 50 y hasta la década de los 70, sin olvidar la pasión del propio E. Serra por la cerámica.

Para Eudald Serra, la cerámica era un objeto sensual y emotivo, y en cartas suyas de 1968 dirigidas a su amigo Llorens Artigas $^{35}$ destacaba que

de todas las artes, la cerámica es la única que, por su belleza, atracción y humanidad, es comparable a la mujer. Además de la forma y el color, nos proporciona el placer del tacto y, por qué no, del beso. ¿Acaso no es beso cuando, en las ceremonias del té, unimos nues-

${ }^{31}$ En los años que trabajé en el MEB (entre 1992-2001) tuve la suerte de poder aprender de la mirada de Serra sobre Japón. Tuve numerosas ocasiones de hablar con él y preguntarle sobre el porqué de las especiales características de las colecciones japonesas del MEB, recibiendo su ayuda en todo momento aunque, eso sí, nunca dejó que grabara lo que él llamaba "les nostres converses" (nuestras conversaciones).

32 Llopis, 1964: 45.

${ }^{33}$ En el catálogo Eudald Serra. Rastres de Vida, se recoge una anécdota explicada por él mismo sobre sus inicios y en la que queda clara constatación del interés del Serra escultor por los objetos sencillos y cotidianos: "insistí tanto que quería ser escultor que mi padre me llevó al taller de Enric Clarasó, un hombre enorme con barba larga y amplios faldones. Alli, entre sus esculturas clásicas, hice una composición con una lata de tabaco y una algarroba" MARZÁ, 1998: 37-38.

${ }^{34}$ Moeran, 1981: 90.

${ }^{35}$ Tanto Eudald Serra como Llorenç Artigas fueron amigos, conocedores y admiradores de la cerámica japonesa y ambos colaboraron en numerosas exposiciones. En la década de los 50 (entre 1953 y 1955), por ejemplo, presentaron una exposición anual con el trabajo de ambos en la Sala Gaspar de Barcelona.

Arch. esp. arte, LXXXVI, 343, JULIO-SEPTIEMBRE 2013, 221-236, ISSN: 0004-0428 
tros labios a los de un bol al tiempo que lo acariciamos amorosamente entre nuestras manos para saborear su tibio contenido? ${ }^{36}$.

Y la apreciación y sensibilidad de Serra hacia la cerámica, exceptuando quizás las altas cotas de sensualidad que él le otorga, la podemos considerar como plenamente mingei. Cuando E. Serra hablaba de la cerámica, en especial en los textos de los últimos años que recogían sus ideas, lo hacía prácticamente en los mismos términos de funcionalidad y belleza que el ideario Mingei utilizaba para definirla. Anatxu Zabalbeascoa, en su artículo para el catálogo de la exposición retrospectiva que la ciudad de Barcelona dedicó a Serra, destacaba cómo de la cerámica a Serra le interesaba que "la decoración estaba supeditada a la función. La unión de lo útil y lo bello, la identificación entre lo funcional y la belleza" ${ }^{37}$. Y, tal y como hemos visto, una de las características principales de los objetos mingei era su funcionalidad, funcionalidad que derivaba en belleza, ya que "Yanagi argumentaba que los objetos mingei eran bellos a causa de que se utilizaban. Un recipiente, por ejemplo, fue hecho no para ser mirado sino utilizado; sólo cuando había sido utilizado se podía decir que era bello. Si un objeto no se utilizaba, perdía su razón de ser"38.

Al estudiar la colección de cerámica japonesa que se conserva en el MEB se observa que Serra no sólo adquirió obras en los principales hornos y centros cerámicos sino que también incluyó producciones de los más destacados ceramistas del momento, quedando así patente tanto su sensibilidad como su conocimiento hacia las características estéticas de la cerámica tradicional japonesa y el valor de sus obras ${ }^{39}$. Así, en la expedición que dirigió en 1961 (correspondiente a los expedientes del museo 121 y 122) Eudald Serra compró obras de artistas que habían sido galardonados años anteriores con el prestigioso premio de cerámica Nihon Toji Kyokai Awards, instituido en 1954 por la Japan Ceramic Society ${ }^{40}$. Funaki Kenji (1927) ${ }^{41}$ lo ganó en 1958, Suzuki Osamu (1926-2001) ${ }^{42}$ y Kawamoto Goro (1919-1986) ${ }^{43}$ en 1959, Yamada

\footnotetext{
${ }^{36}$ Cita recogida por Rubert De Ventós, 1992: 2. Hemos escogido esta cita, pero en realidad esta misma idea la utilizó de manera recurrente a lo largo de toda su vida al referirse a la cerámica. Por citar sólo algunos ejemplos, en una entrevista publicada en 1953 en La Vanguardia (véase Del Arco, 1953: s/p) y ante la pregunta del periodista sobre si la cerámica era un arte menor en relación a la escultura él respondía de manera enérgica y categórica: "No, iprotesto!; la cerámica es tan arte mayor como la escultura y la pintura, y la supera en que además de ser bella arte, tiene un sentido utilitario, y sirve para algo más que su contemplación. Una obra de cerámica tiene la forma, el color, la enorme ventaja de la calidad de la materia y puede verse, tocarse, e incluso ser besada, así una taza de té se lleva a los labios". Y en una de sus últimas entrevistas, con motivo de la exposición retrospectiva de 1998, la periodista Olga SpIEgel, 1998: 37 recogía cómo Serra explicaba "No soy ceramista, soy escultor - puntualiza- pero tengo un conocimiento profundo de la cerámica y la entiendo mejor que nadie porque he tenido mucho contacto con grandes ceramistas de Japón. La aprendí allí. Yo era un gran fan de la ceremonia del té, de la autentica, no la que ven muchos extranjeros, y la ceremonia del te tiene una base importante de humildad. Para mí la cerámica es el arte que tiene más humanidad, el que más se parece a la mujer, la puedes tocar, acariciar, besar. El bol de cerámica lo tiene todo, es un contenedor y cuando te lo pones en a boca es como un beso".

${ }^{37}$ ZaBALBEASCOA, 1998: 94.

${ }^{38}$ Moeran, 1997: 33-34.

${ }^{39}$ Cerámica y porcelana japonesa que ya se coleccionaba en Europa, especialmente desde finales del siglo XIX, aunque los coleccionistas occidentales se inclinaban más por obras del tipo Satsuma, Kutani o Kyoto, mientras que los japoneses coleccionaba un tipo de cerámica radicalmente diferente, una cerámica modesta, sencilla y contenida como las obras de hornos tradicionales de Seto, Iga, Tamba, Mashiko, Shigaraki y Bizen. Y fueron precisamente estos últimos los que Serra priorizó en sus compras para el MEB.

${ }^{40}$ La Japan Ceramic Society, o Nihon Toji Kyokai fue fundada en 1945.

${ }^{41}$ MEB 121-518, MEB 121-519. Expediente 121. Primera parte de la expedición a Japón en 1961. Archivo MEB, página 65 .

${ }^{42}$ MEB 121-89, MEB 121-90, MEB 121-91. Expediente 121. Primera parte de la expedición a Japón en 1961. Archivo MEB, página 12.

${ }^{43}$ MEB 122-24. Expediente 122. Segunda parte de la expedición a Japón en 1961. Archivo MEB, página 3.
} 
Hikaru (1924-2001) $)^{44}$ en 1960 y los ganadores de 1961 fueron Fujiwara Key (1899-1983) ${ }^{45}$ y Taniguchi Ryozo (¿?-1996) ${ }^{46}$. En el MEB también encontramos obras de los primeros ceramistas reconocidos con el título de Tesoro Nacional Viviente (ningen kokuhô) $)^{47}$ como Hamada Shoji $(1894-1978)^{48}$ y Arakawa Toyozo (1894-1985) ${ }^{49}$ en 1955, y Kaneshige Toyo (1896-1967) $)^{50}$ en 1956.

En su diario de viaje encontramos numerosas anotaciones sobre los artistas seleccionados: información técnica sobre el tipo de horno que visitaba, quién era el artesano, qué materiales utilizaba, cuáles eran las técnicas de elaboración y decoración, cómo eran los talleres y entornos de trabajo, etc. Junto a estos detalles técnicos hay información más personal, como las valoraciones que el propio Serra realizaba en relación a determinadas obras y/o ceramistas. Informaciones que en ocasiones completaba en los expedientes o inventarios de campo ${ }^{51}$ con datos más técnicos como temperaturas de cocción, etc. Así por ejemplo, sobre Kaneshige Toyo dice "29-5-61: Lunes. (...) a las 11:45 salgo para Imbei, Bizen. He visitado a Mr. Kaneshige Toyo, una buena casa y buena cerámica, precios muy altos de 30 a 100 mil yenes, no me decido, mañana veré, sin querer desmerecer al artista es un tipo de cerámica donde la forma depende del artista pero en los tonos hay una gran parte de suerte, de todas maneras saber seleccionar ya es todo un arte y sus piezas tiene personalidad". Finalmente, tal y como queda constancia en el inventario de campo, Serra acabó comprando un chawan o bol para la ceremonia del té por 3000 yenes, así como una obra de su hijo, Kaneshige Michiake (1934-1995) ${ }^{52}$, en aquel momento un desconocido joven de 27 años pero que años más tarde, concretamente en 1979, ganaría el preciado galardón Nihon Toji Kyokai Awards de la Japan Ceramic Society.

Es por tanto absolutamente destacable su conocimiento de la cerámica japonesa, así como su especial sensibilidad y gusto estético, que hizo que no sólo comprara obras de artistas ya consagrados y reconocidos, sino también de artistas que, aunque en aquellos momentos eran desconocidos, posteriormente recibieron esos galardones. Así en el Museo Etnológico encontramos una importante selección de obras de reconocidos artistas. Por ejemplo, un acontecimiento destacado en su diario es la visita al taller de Fujiwara Key (fig. 3) y su hijo el 30 de

${ }_{44}$ MEB 121-105. Expediente 121. Primera parte de la expedición a Japón en 1961. Archivo MEB, página 14.

${ }_{45}$ MEB 121-208, MEB 121-209, MEB 121-210. Expediente 121. Primera parte de la expedición a Japón en 1961. Archivo MEB, página 27.

${ }^{46}$ MEB 121-47. Expediente 121. Primera parte de la expedición a Japón en 1961. Archivo MEB, página 6.

47 En realidad, "Tesoros Nacionales Vivientes" es el nombre por el cual se conoce popularmente a los artesanos destacados como "Propiedad Cultural Importante e Intangible". Esta figura surgió de la ampliación realizada en 1954 de la Ley de Protección de Propiedades Culturales, promulgada en 1950 como una manera de proteger las propiedades culturales y las artes tradicionales, así como a aquellos que las practicaban. Según esta ley, se va nombrando a ciertos artesanos destacados "Propiedad Cultural Importante e Intangible", como una manera de preservar, conservar y difundir su arte. Para más información de todo el proceso de selección y nombramiento véase Intangible Cultural Heritage. Protection System for Intangible Cultural Heritage in Japan (en línea: http://www.bunka.go.jp/bunkazai/pamphlet/pdf/ pamphlet_en_05.pdf,) así como la web de la Agency for Cultural Affairs of Japan (http://www.bunka.go.jp/english/).

${ }_{48}$ MEB 121-561, MEB 121-562, MEB 121-563, MEB 121-564. Expediente 121. Primera parte de la expedición a Japón en 1961. Archivo MEB, página 71.

${ }^{49}$ MEB 121-25, MEB 121-26, MEB 121-27, MEB 121-28, MEB 121-29, MEB 121-30, MEB 121-31. Expediente 121. Primera parte de la expedición a Japón en 1961. Archivo MEB, página 4. MEB 121-32, MEB 121-33, MEB 12134, MEB 121-35, MEB 121-36. Expediente 121. Primera parte de la expedición a Japón en 1961. Archivo MEB, página 5.

${ }^{50}$ MEB 121-212. Expediente 121. Primera parte de la expedición a Japón en 1961. Archivo MEB, página 27.

${ }^{51}$ Realizados por Eudald Serra en sus viajes a Japón y que se custodian en los archivos del MEB. En esta documentación (fuentes manuscritas) se encuentran toda una serie de datos básicos sobre el objeto adquirido en las distintas campañas de compra llevadas a cabo en el archipiélago nipón.

52 MEB 121-213. Expediente 121. Primera parte de la expedición a Japón en 1961. Archivo MEB, página 27. 


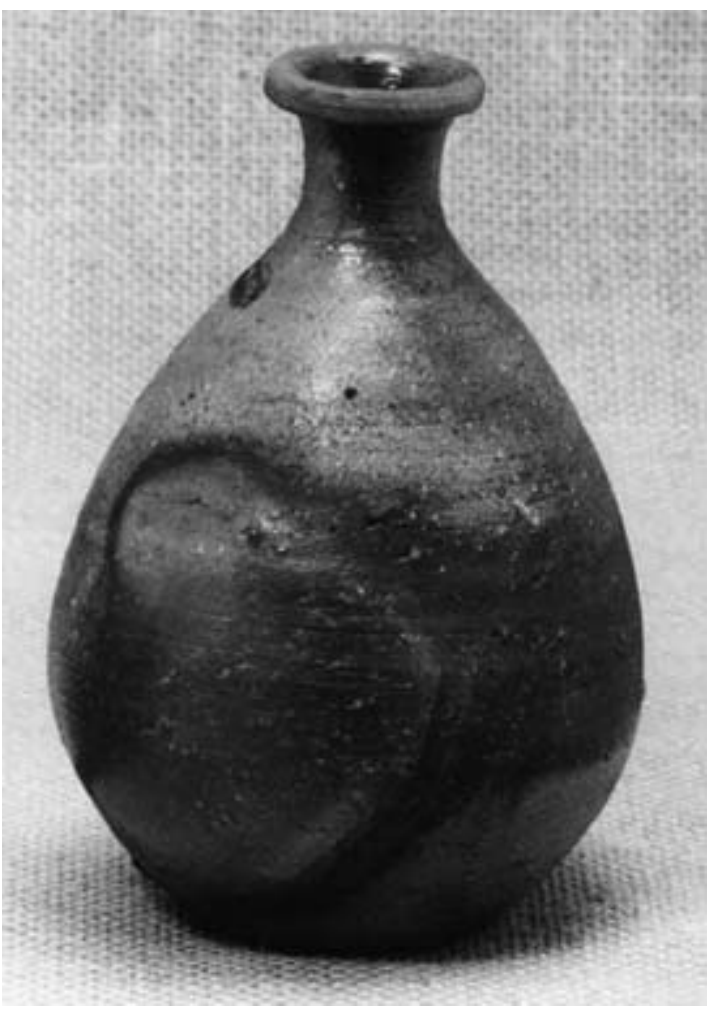

Fig. 3. Fujiwara Key, Tokkuri, botella de sake. Horno Bizen, prefectura de Okayama, Japón. Cerámica, 14.5 x $10.5 \mathrm{~cm}$. (C) Fotografía Pilar Aymerich cortesía del Museu Etnològic de Barcelona. mayo de 1961 (año en que ganó el premio de la Japan Ceramic Society), uno de los artistas más importantes de la tradición de Bizen. Pocos años más tarde, en 1970, en Fujiwara Kei obtuvo el título de Tesoro Nacional Viviente, mientras su hijo, Fujiwara Yu (1932$2001)^{53}$ fue distinguido como Tesoro Nacional Viviente en 1996.

30-5-61: martes. (...) Visito luego al ceramista Fujiwara (a una hora de Imbei). Le encuentro con su hijo. Me ofrecen de comer y empezamos a ver piezas. Son de una gran amabilidad y sencillez. El padre muy generosamente ha ofrecido como obsequio dos magníficas piezas para el Museo ${ }^{54}$. He comprado dos piezas más, una pequeña al padre ${ }^{55}$ y otra al hijo ${ }^{56}$. En vista de mi interés por la cerámica de Bizen, nos vamos juntos con el hijo a Okayama, visitamos algunos anticuarios. Pocas piezas, buenas y caras. Me invita a cenar y a tomar unas cervezas. Regresamos con el padre, me ofrece una magnífica botella "Abura bin" ko-bizen del 1600, magnífica. El hijo me ha ofrecido una de sus piezas, muy buena, y el padre otra botella para que tenga un recuerdo suyo ${ }^{57}$. Me avergüenza tanta amabilidad. He dormido en una pieza de recibir rodeado de magníficas piezas del padre y del hijo y otras de antiguas, es un lugar tranquilo cerca del mar. Tanto Kaneshige como Fujiwara son ceramistas de renombre y se cotizan sus piezas.

Junto al ejemplo de la familia Fujiwara existen muchos otros, como Kondo Yuzo (1902-1985) ${ }^{58}$, instituido como Tesoro Nacional Viviente en 1977, Miwa Kyusetsu XI (1910-i? $)^{59}$, Tesoro Nacional Viviente en 1983 y premio especial del 50 aniversario de los premios Japan Ceramic Society de

53 MEB 121-211. Expediente 121. Primera parte de la expedición a Japón en 1961. Archivo MEB, página 27.

${ }^{54}$ MEB 121-208 (bol con plato) y MEB 121-210 (gran plato) Expediente 121. Primera parte de la expedición a Japón en 1961. Archivo MEB, página 27.

${ }_{55}$ MEB 121-209 (botella de sake). Expediente 121. Primera parte de la expedición a Japón en 1961. Archivo MEB, página 27.

${ }_{56}$ MEB 121-211 (florero o botella). Expediente 121. Primera parte de la expedición a Japón en 1961. Archivo MEB, página 27.

${ }^{57}$ Estas piezas debieron pasar a la colección particular del propio Serra, ya que no están en los fondos del MEB.

${ }^{58}$ MEB 121-619, MEB 121-620. Expediente 121. Primera parte de la expedición a Japón en 1961. Archivo MEB, página 78.

${ }_{59}$ MEB 121-487. Expediente 121. Primera parte de la expedición a Japón en 1961. Archivo MEB, página 61. MEB 121-488, MEB 121-489. Expediente 121. Primera parte de la expedición a Japón en 1961. Archivo MEB, página 62. 
2003, Shimaoka Tatsuzo (1919-2007) ${ }^{60}$, discípulo de Hamada, que fue escogido como Tesoro Nacional Viviente en $1996^{61}$. Así como numerosos galardonados del Japan Ceramic Society como Kondo Yutaka (1933-1983) ${ }^{62}$ en 1966 y Yagi Kazuo (1918-1979) en 1972.

Ya hemos explicado cómo la apreciación del arte de la cerámica por parte de Eudald Serra, una apreciación que hemos determinado en calificar como plenamente mingei, probablemente deriva directamente de su relación y afinidad personal con Hamada Shoji (1894-1978) ${ }^{63}$, uno de los ceramistas japoneses más célebres y conocidos a nivel internacional. "17-6-1961 Sabado: (...) Salgo para Mashiko, veo a Hamada. Vive en una esplendida casa de campo, con dos o tres hornos y una cantidad de piezas magníficas suyas y de su colección de piezas japonesas antiguas, koreanas, etc. Después de mucho mirar he comprado bastantes piezas para el museo y para mí. Visito otro artista local discípulo de Hamada, muy bueno le compro varias piezas, me quedo a dormir en Mashiko" (fig. 4).

Según destacaba Serra, fue de Hamada de quien aprendió a amar la cerámica, "que es un amor apasionado por un arte humilde" ${ }^{\prime 64}$. Un arte, el de la cerámica, que aúna los cuatro elementos: tierra, aire, agua y fuego y

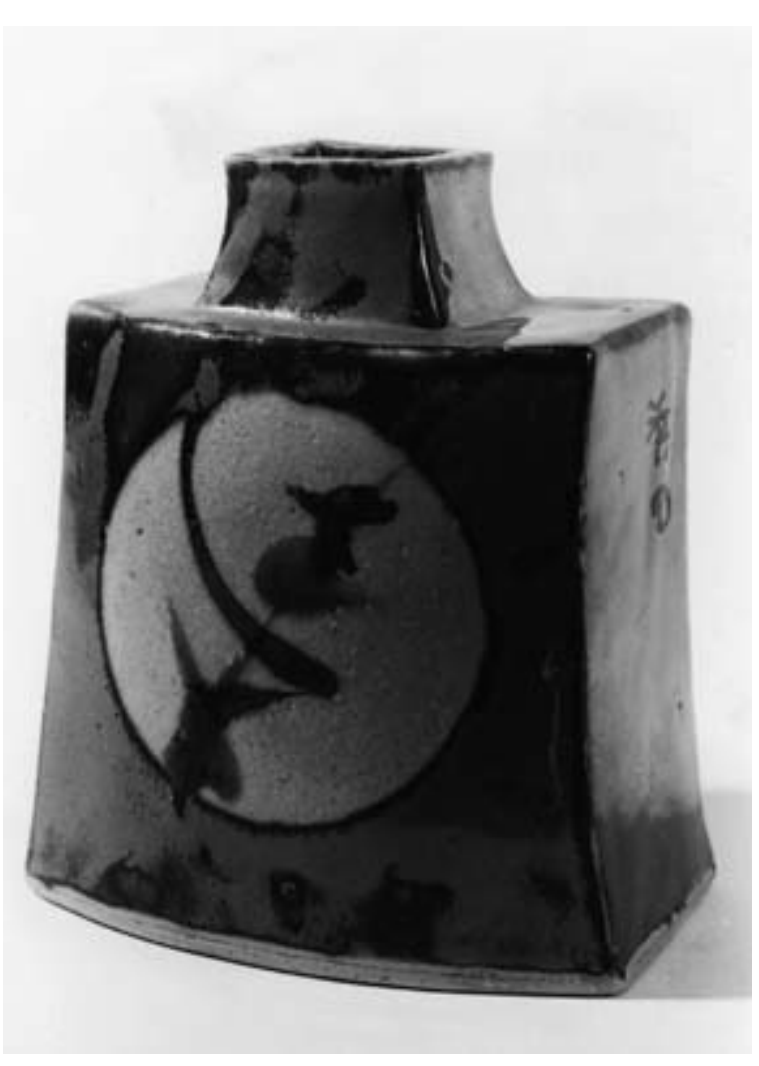

Fig. 4. Hamada Shoji, Henko, botella. Horno Mashiko, Prefectura de Tochigi, Japón. Gres vidriado, 25.5 x 21 x $13.5 \mathrm{~cm}$. (C) Fotografía Pilar Aymerich cortesía del Museu Etnològic de Barcelona.

${ }^{60}$ MEB 121-565, MEB 121-566, MEB 121-567. Expediente 121. Primera parte de la expedición a Japón en 1961. Archivo MEB, página 71.

${ }^{61}$ En esta trascripción, tras el diario personal de viaje encontramos una relación de los gastos de viaje, y así podemos observar la diferente valoración que en aquel momento tenían las obras de Hamada respecto a las de su discípulo: las cuatro obras de Hamada que compró le costaron 67.000 yenes de la época, mientras que por las tres de su discípulo pagó 10.000 yenes (valores del año 1961). Esta misma información también aparece reflejada en los inventarios de campo realizados por E. Serra para el MEB: MEB 121-83, MEB 121-84, MEB 121-85, MEB 121-86, MEB 121-87. Expediente 121. Primera parte de la expedición a Japón en 1961. Archivo MEB, página 11. MEB 121-88. Expediente 121. Primera parte de la expedición a Japón en 1961. Archivo MEB, página 12.

${ }_{62}^{62}$ MEB 121-621. Expediente 121. Primera parte de la expedición a Japón en 1961. Archivo MEB, página 78.

${ }_{63}$ Serra siempre destacó su relación con Hamada Shoji. Uno de los aspectos que Serra destacaba era que, al igual que hacía él, Hamada «iba por el mundo y recogía cosas, cosas que le recordaban las tradiciones populares de Japón a pesar que, por su procedencia lejana, era imposible que derivasen» ZABALBEASCOA, 1998: 84. La conexión entre ambos era tal que "Cuando viajamos juntos -explica Serra-, delante de una tela o de un cofre de madera, él sabía reconocer en mi cara qué opinaba sobre lo que nos mostraban. A pesar de que los dos hablábamos inglés, entre nosotros las cosas se descubrian por la vista. En la vida no es necesario hablar tanto. A lo largo de la vida, uno tiene esta comunicación callada con muy pocas personas. Se da cuando alguien, más que conocerte, parece que te adivine» ZABALBEASCOA, 1998: 86.

${ }^{64}$ Zabalbeascoa, 1998: 86. 
que nos conecta con la vida cotidiana del hombre a través de la historia. Un arte que vincula belleza y funcionalidad, dos aspectos esenciales para entender a Serra y su particular concepto de arte.

Este amor por Japón, por su arte, por su cerámica, ¿se deja ver en su producción artística? Al regresar a Barcelona a finales de la década de 1940, Serra volvió a contactar con la vanguardia del momento, como fue la Escuela de Altamira ${ }^{65}$, y volvió a exponer tanto en galerías y museos nacionales como internacionales ${ }^{66}$, dejando la figura únicamente para documentar sus viajes con el MEB o con la Fundación Folch. Pero cuando se le preguntaba si había influencias de otras culturas en su obra artística su respuesta siempre era un rotundo $\mathrm{no}^{67}$. Rubert de Ventos, en el catálogo de una exposición de obra de Serra consideraba que "contra lo que se ha dicho a menudo, yo no encuentro en la obra de Eudald Serra demasiadas influencias formales de la cultura japonesa o aborigen que, desde sus veinte años no ha dejado de patear. Lo que de estas culturas ha adoptado es más bien un modo de ver y tratar la propia" ${ }^{\prime 68}$ (fig. 5).

Realmente, en sus obras lo que encontramos es un respeto hacia los materiales utilizados, una clara fluidez formal, un diálogo entre vacío y plenitud, formas orgánicas que en ocasiones se han llegado a calificar de totémicas, un gusto por la cotidianidad, un aprecio en el juego de texturas. Una obra, la de Serra, en la cual encontramos condensadas todas sus vivencias, obsesiones, gustos y experiencias personales por lo cual fluye entre la figuración y la abstracción según el momento y el lugar. Pero por encima de todo, lo que podemos observar es una nueva formar de mirar, de comprender y de concebir el arte. Una nueva forma de mirar en la que reparamos cómo, igual que sucede en el arte tradicional de Asia oriental, él no diferencia entre arte y artesanía. Este es un aspecto básico que lo conecta directamente con el pensamiento y el gusto tradicional japonés ya que, como señala Robert Moes, "los japoneses nunca habían reconocido esta básica distinción entre «arte», o «bellas artes» (pintura, escultura, arquitectura) por un lado, y «artesanía» o «artes aplicadas» (cerámica, textiles, trabajo con la madera, laca, cestería, papel) por el otro, como sí hacemos en Occidente" ${ }^{69}$, ya que esta arbitraria distinción fue introducida en Japón durante el período de la Restauración Meiji (1868-1912), una época de apertura caracterizada por la modernización y la occidentalización del país.

La exposición retrospectiva celebrada en la ciudad de Barcelona en $1998^{70}$ lo definía perfectamente, ya que en ella se mostraba la generosidad de la persona y su manera de entender y concebir el arte: en su propia retrospectiva había obra propia pero también un claro reconocimiento y admiración hacia la obra de los «otros», en la gran cantidad de obras seleccionadas por él mismo de

${ }^{65}$ Eudald Serra asistió a las reuniones que entre 1949 y 1950 se organizaron en Santillana de Mar junto a artistas destacados del momento Para información sobre la Escuela de Altamira véase BozAL, 1995: 233-235 y especialmente el catálogo de la exposición: Frances, Fernando; Huice, Fernando. La escuela de Altamira, cat. expo, Gobiernos de Cantabria, 1998.

${ }^{66}$ Por lo que respecta a las exposiciones de estos años destacar las de la Sala Gaspar (Barcelona, 1964), la Exposición Universal de Nueva York (1964) y en la Galería Trece (Barcelona, 1979 y 1981). Pero no será hasta la década de 1980, cuando deja de dirigir las expediciones del MEB y la Fundació Folch, que retorna a su obra y participa en relevantes exposiciones internacionales como: "Escultura española 1900-1936" (Madrid, 1986), "Homage to Barcelona (Londres, 1985), "Qu'est-ce que la sculpture moderne" (Pompidou, Paris, 1986), "Surrealisme a Catalunya" (Barcelona 1988), "Picasso, Miró, dalí y los orígenes del arte moderno en España" (MNCARS y Frankfurt, 1991), "Eudald Serra: esculturas antropológicas" (MEB, 1992), instalación pública en Barcelona de la obra Forma i espai (1992), "Las vanguardias en Catalunya, 1906-1939" (Barcelona, 1992), "El surrealismo en España" (MNCARS, Madrid y Kunsthalle, Dusseldorf, 1995), “Antes del informalismo" (MNCARS, 1996), "Grup R" (CCCB, 1997), "Eudald Serra. Rastres de vida" (Barcelona, 1998), entre otras.

${ }^{67}$ Véase por ejemplo la entrevista realizada por NOGUERo, 1999: 35-36.

${ }^{68}$ Rubert De Ventós, 1992: 2.

${ }^{69}$ MoEs, 1997: 17.

${ }^{70}$ Exposición, titulada Eudald Serra. Rastres de vida [Rastros de vida], comisariada por Ferran Marzá y Pepe Serra y celebrada en el Palau de la Virreina de Barcelona entre el 20 de octubre de 1998 al 14 de febrero de 1999. 


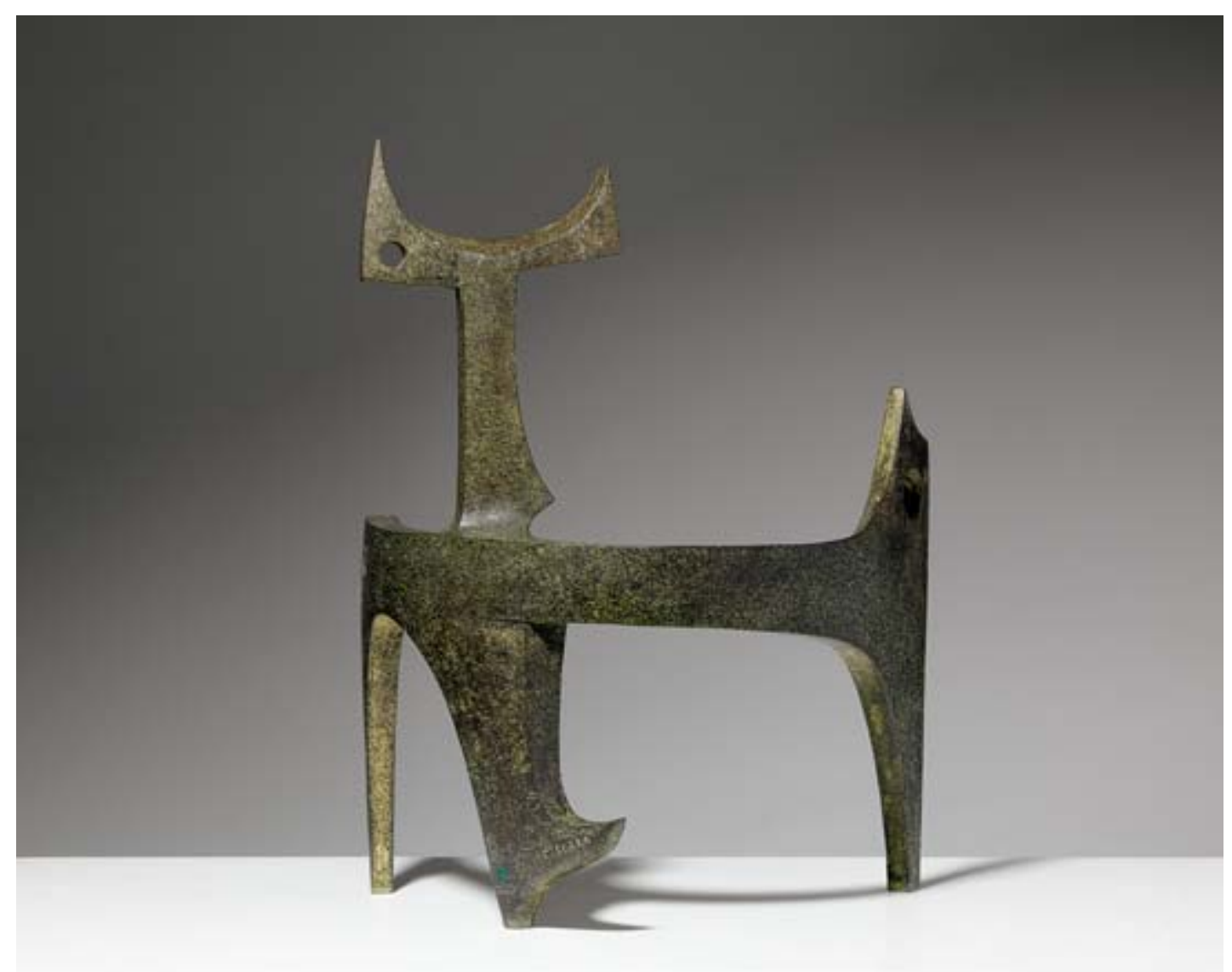

Fig. 5. Eudald Serra, Forma i espai, 1966. Bronce patinado 43 x 33,5 x 19 cm. Colección MACBA. (C) MACBA - Museu d'Art Contemporani de Barcelona.

entre todas aquellas recogidas a lo largo de su vida y sus viajes. Entre la selección que el propio Eudald Serra realizó para dicha exposición había cinco obras de Hamada, una de Fujiwara Yu y otra de Ueda Naokata de su colección particular: toda una muestra de su particular y personal mundo estético.

\section{Conclusiones}

Una de las grandes aportaciones de Serra al Museo Etnológico de Barcelona es la especial sensibilidad que tuvo para elegir y confeccionar sus colecciones, especialmente las japonesas. Esta especial "sensibilidad", su particular "mirada", reseguida en este artículo, particularizó de una manera muy concreta las colecciones que este artista adquirió para el museo e influyó también en su propia obra.

En relación con el museo se ha de tener cuenta que no es posible pensar en aportaciones asépticas y/o objetivas, así que hemos de valorar la calidad de la percepción personal y como ésta se traduce en la calidad del material seleccionado. Precisamente ésta es una de las particularidades 
que confiere singularidad a las colecciones seleccionadas por Serra para el MEB: cada objeto fue seleccionado y adquirido de manera absolutamente personal, siguiendo sus propias directrices estéticas y su propio interés. Por lo tanto, estamos ante una colección comprada con dinero público, que forma parte de un museo municipal, pero que fue seleccionada con unos criterios y unas características más propias de una colección privada. Una colección miscelánea que tiene el valor de presentar y ejemplificar las preferencias estéticas de E. Serra y la relación que establece con el movimiento Mingei. Pero también una colección pensada y seleccionada para formar parte de un museo y poder mostrar y explicar a través de ella que era y en qué consistía la cultura tradicional japonesa, ya que Serra era plenamente consciente que ya en esa época y pesa a los esfuerzos, estaba desapareciendo. Una colección donde el trabajo de campo forma parte indisociable de su concreción.

Eudald Serra muestra una nueva manera de mirar. Supo desprenderse de la mirada coartada por el propio bagaje cultural y artístico, y aprender a ver, aceptar y apreciar diferentes realidades artísticas. Se trata de una nueva mirada muy acorde con las ideas propugnadas desde el movimiento japonés Mingei, en las cuales Yanagi observaba que no era lo mismo ver la belleza que "conocer o saber sobre la belleza: «ver» es ir directo al corazón; conocer los hechos acerca de un objeto bello es dar vueltas a su alrededor. La discriminación intelectual es menos esencial para la comprensión de la belleza que el poder de la intuición" "71 . Y Serra puso en práctica esta mirada desde la intuición y la sensibilidad, que le permitió conocer y reconocer la belleza incluso en los objetos más comunes, sencillos y cotidianos. Una sensibilidad especial que le permitió seguir siendo él mismo pasando de la abstracción a la figuración, y volver a la abstracción sin perder en ningún momento la propia esencia. Una intuición que le permitió alejarse de la dicotomía y la polémica existente entre figuración y abstracción, manteniendo siempre su propia personalidad, tanto en su propia obra como en la que apreciaba y coleccionaba.

\section{BIBLIOGRAFÍA}

Asenjo Fernández, I, "Ángel Ferrrant y la reforma de las escuelas superiores de Bellas Artes", Archivo Español de Arte, LXXXII, 325, enero-marzo 2009, pp. 47-62.

Blanch, María Teresa, "Eudald Serra. Una regeneradora mirada al ayer". Batik, nº 48, año VII, marzo 1979, pp. 18-19.

Bozal, Valeriano, Arte del siglo XX en España. Pintura y escultura 1939-1990. Editorial Espasa Calpe, 1995.

Brandt, L. Kim, Kingdom of Beauty: Mingei and the politics of folk art in Imperial Japan. Asia-Pacific. Durham, Duke University Press, 2007.

DD.AA. Catálogo de la exposición de cerámica y arte popular japonés. Expedición del Museo Etnológico 1961. Barcelona: Ayuntamiento de Barcelona, 1962.

De Waal, Edmund, "Homo Orientalis: Bernard Leach and the Image of Japanese Craftsman". Journal of Design History, vol. 10, $\mathrm{n}^{\circ}$ 4, 1997, pp. 355-362.

Del Arco, "Mano a mano. Eudaldo Serra". La Vanguardia española, 18-12-1953, p. 13.

Fontdevila, Elena, "L'escultor Serra". En Llorens, E. (comisaria). L'objecte català a la llum del surrealisme, cat. expo. Barcelona, Museu Nacional d'Art de Catalunya, 2007, p. 114-119.

Gómez Pradas, Muriel, El movimiento Mingei en las colecciones del Museu Etnològic de Barcelona. El caso de los kyôdo-gangu o juguetes populares y tradicionales japoneses. Zaragoza, publicación en línea http://zaguan.unizar.es/record/6541, 2011

\footnotetext{
${ }^{71}$ YANAGI, 1989: 110.
} 
Huera, Carmen.; Soriano, Dolores, Escultures antropològiques d'Eudald Serra i Güell, cat. expo. Barcelona, Ajuntament de Barcelona, Fundació Folch, 1991.

Huera, Carmen, “El Museu Etnològic de Barcelona”. Revista d'Etnologia de Catalunya, no 3, 1993, pp. 160-164

Huera, Carmen, "El Museu Etnològic de Barcelona: formación, desarrollo y previsiones de futuro". Anales del Museo Nacional de Antropología, $n^{\circ}$ 2, 1995, pp. 151-163.

Kikuchi, Yuko, Japanese Modernisation and Mingei Theory: Cultural Nationalism and Oriental Orientalis. New York: Routledge Curzon, 2004.

López, Alberto, "La antropología social del arte y el sistema de los objetos". En López, A, Hernández, F, Barragán, JM. (ed) Encuentros del arte con la antropología, la psicología y la pedagogía. Barcelona: Angle Editorial, 1997, pp. 11-48.

Llopis, Arturo,’Un catalán en kimono". Destino, no 587, noviembre 1948, pp. 3-5.

Llopis, Arturo, "Barcelona en los Andes”. La Vanguardia española, 5-04-1964, p. 45.

Marzá, Fernando; Serra, Pepe, "Rastres de vida". En Marzá, F.; Serra, P. (comisarios), Eudald Serra. Rastres de vida, cat. expo. Colección Modernos contemporáneos, 2. Barcelona, Ambit, 1998, pp. 9-12.

Moeran, Brian, "Yanagi, Morris and popular art". Ceramic Review, n 66, November/December, 1980, p. 25 26.

Moeran, Brian, “Japanese Social Organization and the Mingei Movement”. Pacific Affairs, vol. 54, n 1, 1981, pp. 42-56.

Moeran, Brian, Folk Art Potters of Japan. Beyond an Anthropology of Aesthetics. Surrey, Curzon Press, 1997.

Moes, Robert, The Appreciation of Folk Art in Japan. En DD.AA. 'The Beauty of Use'. Mingei, Japanese Folk Craft. Tokyo: CWAJ Lectures Series, 1997, p.17-22.

Noguero, Joaquim, "El viatge de la vida amb Eudald Serra”. Escola catalana, julio, agosto, septiembre 1999, $\mathrm{n}^{\mathrm{o}} 362$, pp. 34-38.

Rubert De Ventós, Xavier, Eudald Serra. Escultures, cat. expo., Barcelona, Galeria Brok, 1992.

Subirachs, Josep María, "L'escultor Eudald Serra”. Butlletí de la Reial Academia de Belles Arts de Sant Jordi, 1999, vol. 13, pp. 329-332.

Spiegel, Olga, «La exposición de la Virreina resume toda mi vida, dice el escultor Eudlad Serra». La Vanguardia 19-10-1998, p. 37.

Teixidor, Joan, Eudald Serra. Barcelona: Ediciones Polígrafa, 1979.

Utsumi, Teiko, Mingei and the Life of Soetsu Yanagi. En DD.AA. Mingei. Two Centuries of Japanese Folk Art. Tokyo: The Japan Folk Arts Museum, 1995, p. 14-31.

Vélez, Pilar, "Eudald Serra Güell (1911-2002)". Butlletí de la Reial Academia de Belles Arts de Sant Jordi, 2002, vol. 16, no 2, pp. 371-374.

Yanagi, Sori, The Unknown Craftsman. Tokyo: Kodansha Int. 1989 [1972].

Zabalbeascoa, Anatxu, "Eudald Serra: vocabulario para un hombre inquieto". En Marzá, F.; Serra, P. (comisarios), Eudald Serra. Rastres de vida, cat. expo. Colección Modernos contemporáneos, 2. Barcelona, Àmbit, 1998, p. 32-129.

Fecha de recepción: 3-VIII-2012

Fecha de aceptación: 16-V-2013

Arch. esp. arte, LXXXVI, 343, JULIO-SEPTIEMBRE 2013, 221-236, ISSN: 0004-0428 